\title{
Role of Mast Cells in the Pathogenesis of Pruritus in Mastocytosis
}

\author{
Dominika KWIATKOWSKA and Adam REICH \\ Department of Dermatology, Institute of Medical Sciences, Medical College of Rzeszow University, Rzeszów, Poland
}

\begin{abstract}
Pruritus can be defined as an unpleasant sensation that evokes a desire to scratch and significantly impairs patients' quality of life. Pruritus is widely observed in many dermatoses, including mastocytosis, a rare disease characterized by abnormal accumulation of mast cells, which can involve skin, bone marrow, and other organs. Increasing evidence highlights the role of mast cells in neurogenic inflammation and itching. Mast cells release various pruritogenic mediators, initiating subsequent mutual communication with specific nociceptors on sensory nerve fibres. Among important mediators released by mast cells that induce pruritus, one can distinguish histamine, serotonin, proteases, as well as various cytokines. During neuronal-induced inflammation, mast cells may respond to numerous mediators, including neuropeptides, such as substance $P$, neurokinin A, calcitonin gene-related peptide, endothelin 1, and nerve growth factor. Currently, treatment of pruritus in mastocytosis is focused on alleviating the effects of mediators secreted by mast cells. However, a deeper understanding of the intricacies of the neurobiology of this disease could help to provide better treatment options for patients.
\end{abstract}

Key words: itch; mast cells; mastocytosis; pruritus.

Accepted Oct 13, 2021; Epub ahead of print Oct 13, 2021

Acta Derm Venereol 2021; 101: adv00583.

Corr: Adam Reich, Department of Dermatology, University of Rzeszow, UI. Szopena 2, PL-35-055 Rzeszów, Poland. E-mail: adamandrzejreich@ gmail.com

$\mathrm{P}$ ruritus can be defined as a subjective, unpleasant sensation that evokes a desire to scratch. This phenomenon is a prevalent feature of many skin diseases, including mastocytosis $(1,2)$. In the molecular mechanism of itching, mast cells are important players. These versatile innate immune cells also have an integral role in the pathogenesis of mastocytosis (3). Of note, the term mastocytosis is broad, and encompasses a group of systemic variants of mastocytosis as well as cutaneous manifestations without any systemic involvement, the latter including maculopapular cutaneous mastocytosis (also termed urticaria pigmentosa), diffuse cutaneous mastocytosis, and localized mastocytoma of the skin (4). Systemic mastocytosis, which encompasses approximately $20 \%$ of all mastocytosis cases, includes indolent systemic mastocytosis, smouldering systemic mastocytosis, systemic mastocytosis with haematological neoplasm, aggressive systemic mastocytosis, mast cell leukaemia and mast cell sarcoma (4).

\section{SIGNIFICANCE}

The term mastocytosis refers to a disorder characterized by the accumulation of mast cells in various organs. Mast cells play a crucial role in neurogenic inflammation and may induce pruritus via the release of several neuromediators, including histamine, serotonin, proteases, and various cytokines; however, studies focusing on pruritus in mastocytosis are quite limited. The current review provides an in-depth literature review on the pathogenesis of pruritus in mastocytosis.

The hyperplasia of mast cells within various tissues remains crucial in mastocytosis (5). The biological function of mast cells is thought to be strongly associated with the c-KIT receptor expressed on mast cells (6). Binding of stem cell factor (SCF) to the extracellular domains of the c-KIT receptor (CD117) induces the proliferation and maturation of mast cells and intensifies the release of various mediators. The manifestations of mastocytosis are a consequence of the alterations in the KIT gene structure and its constitutive activation, independent of its ligand. This leads to mast cell hyperplasia, which can involve skin, bone marrow, and internal organs (4). Studies have shown diverse mast cell functions, fulfilling both negative and positive immunoregulatory roles, which contribute to various pathological conditions, but also maintain homeostasis $(7,8)$. Heterogeneity of mast cells constitutes their complex role, not only as effector cells in allergic reactions, but also as part of the innate and adaptive immune system (9). The sensitivity of mast cells to various microenvironmental signals determines their importance in the pathogenesis of many biological processes, including pruritus. Moreover, increasing data suggest a significant role of mast cells in neurogenic inflammation and, thus, in the pathogenesis of pruritus through neuroimmunological interactions $(10,11)$. In clinical practice, pruritus seems to be a common and troublesome symptom in patients with mastocytosis. However, knowledge of the molecular basis of pruritus in mastocytosis remains limited, making it difficult to select an effective antipruritic treatment for these patients.

This review summarizes the current understanding of the molecular mechanisms of pruritus in mastocytosis.

\section{EVIDENCE SEARCH}

For the purposes of this review, a detailed search of PubMed database was carried out, using the following 
search terms: "mast cells" or "mastocytosis" or "urticaria pigmentosa" combined with "itch" or "pruritus" or "pruritus pathogenesis" or "proinflammatory mediators" or "neurogenic inflammation" or "histamine" or "serotonin" or "proteases" neuropeptides (Fig. 1). Articles were selected based on their relevance regarding the topic of this review. In addition, all studies published in languages other than English were excluded. Several articles were also included by manual search during the investigation of references in other papers. A final total of 107 articles were included in the analysis.

\section{ORIGIN AND DEVELOPMENT OF MAST CELLS}

Developmentally, mast cells are derived from the CD34 ${ }^{+}$ pluripotent progenitor cells from the bone marrow (12). Subsequently, CD34 ${ }^{+}$cells differentiate into mast cell precursors $(\mathrm{MCP})$ that circulate in the peripheral blood (13). MCP transmigrate to connective or mucosal tissues through the blood. In the presence of SCF and other cytokines, MCP transform into $\mathrm{KIT}^{+}$and $\mathrm{FceR} 1^{+}$cells (14). Terminally differentiated and mature mast cells with characteristic cytoplasmic granules reside in tissues. Mast cells are found in close proximity to myelinated and unmyelinated neural structures, as well as blood and lymphatic vessels $(15,16)$. These specific locations are closely correlated with mast cell function, which encompasses the capacity to release a multitude of proinflammatory mediators, immunoregulatory cytokines,

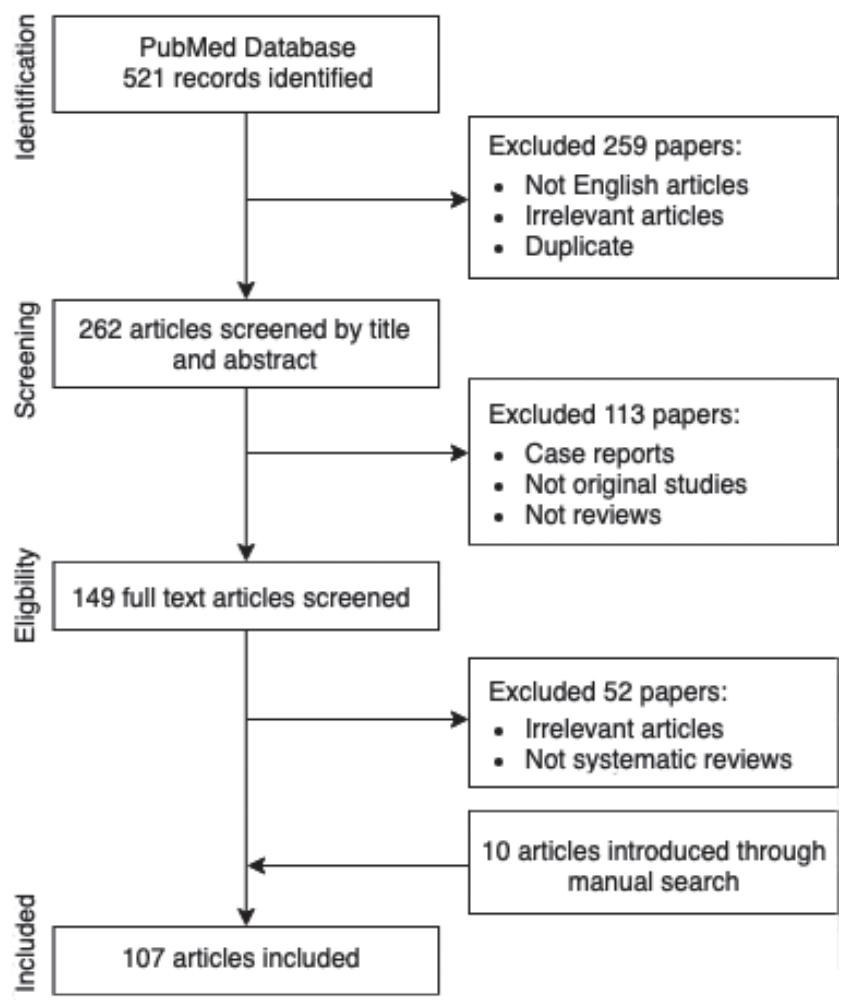

Fig. 1. Flowchart of PubMed database search. and chemotactic factors. Because of large differences in protease content and staining with chromogenic dyes, mast cells in rodents have been divided into mucosal and connective tissue subtypes (17). The connective tissue subtype, in contrast to the mucosal one, showed stabilization after utilization of disodium cromoglycate in both, in vitro and in vivo rat models $(18,19)$. Interestingly, disodium cromoglycate was largely ineffective and did not inhibit connective tissue mast cell activation in the mouse (20), and its potential biological activity in humans remains largely controversial.

In humans, individual protease compositions are of paramount importance in dividing mast cells into subsets. Currently, it is possible to distinguish the following cutaneous mast cell subtypes: mast cells containing tryptase (MCT), chymase (MCC), or both (MCTC) (7). However, mast cells demonstrate significant heterogeneity, which reflects complexity of interactions between microenvironment and specific anatomical locations.

\section{MAST CELLS AND NEUROGENIC INFLAMIMATION}

The neurophysiology of pruritus involves the combined action of nerve fibres that transfer itching peripherally and centrally, along with the abundance of itch mediators released in the microenvironment (21). Free nerve endings in the epidermis are particularly important for sensing pruritic stimuli. The aforementioned peripheral sensory neurones are mainly divided into myelinated A-delta fibres and unmyelinated $\mathrm{C}$-fibres, whereas $\mathrm{C}$-fibres are further subdivided into peptidergic and non-peptidergic fibres (22). Scratching behaviour promotes the secretion of neuropeptides from sensory nerve endings, which enhances neurogenic inflammation. The itch signal is conveyed to secondary neurones distributed in the dorsal horn of the spinal cord and then to the brain, thus intensifying the mutual cycle of itching and scratching (21).

Most mast cells are found in the dermis, especially in perivascular areas, unlike in the epidermis of normal skin, where they are absent (23-25). However, the distribution of mast cells in close proximity to the nerve endings in the epidermis and meninges has been observed (26). Epidermal mast cells can also be detected in several pathological conditions associated with chronic inflammation. Research has shown significant alterations in the density of mast cell between proximal and distal body sites, with the highest numbers in distal extremities and forearms (27). Whether this particular distribution is correlated with the exposure of different parts of the body to external factors, such as ultraviolet light, remains controversial.

In addition to the anatomical association, there is a functional reciprocal communication pathway between mast cells and free nerve endings (28). Molecular mechanisms that mediate intracellular communication include the release of various mediators by mast cells, which can 
modulate sensory nerves via the activation of receptors on nerve terminals. This process stimulates the sensory nerve endings to express neuropeptides and creates the loop of the vicious cycle that increases neurogenic inflammation and its associated itch (29). Moreover, both mast cells and nerves can express related receptors and may respond to stimulation by the same mediators, which further enhances mutual interactions.

\section{PRURITUS FROM A MOLECULAR POINT OF VIEW}

In response to various stimuli, mast cells release a variety of proinflammatory mediators that contribute to the pathogenesis of pruritus (Fig. 2). Histamine is the best-known endogenous agent that evokes itch (30). Nevertheless, the pathogenesis of pruritus in mastocytosis can be, at least partially, histamine independent.

\section{Histamine}

Histamine is stored primarily in the granules of tissue mast cells, which are present in most tissues and are particularly abundant in the skin. Histamine is a well-known mediator in the development of rapid anaphylactic reactions and allergic responses. In mastocytosis, patients may demonstrate elevated serum histamine levels (2). The role of histamine in scratching behaviour has been reported extensively. This pruritogenic neurotransmitter is released from the granules of dermal mast cells in response to different stimuli, such as acute ultraviolet light B (UVB) injury (31). The subcutaneous injection of histamine elicits the triple response, namely a red spot due to vasodilatation, flare, which is the consequence of an axon reflex, and a wheal due to increased permeability of blood vessel walls. Mast cells are characterized by expression of the high-affinity receptor for IgE, FceRI, and the capacity to synthesize histamine. Histamine binds to $4 \mathrm{G}$ protein-coupled receptors (GPCRs), H1receptor (H1R), H2-receptor (H2R), H3-receptor (H3R), H4-receptor (H4R), respectively. H1R and H4R have been shown to play an important role in allergy and inflammation, H2R can alter gastric acid secretion, and $\mathrm{H} 3 \mathrm{R}$ is involved in regulating the release of various neurotransmitters in the brain, making it crucial in neuroinflammatory diseases $(32,33)$. Stimulation of H1R activates the phospholipase $\mathrm{C}$, inositol 1,4,5-trisphosphate, $\mathrm{Ca}^{2+}\left(\right.$ PLCIP3 $\left.\mathrm{Ca}^{2+}\right)$ pathway and mediates symptoms of type I allergic reactions, such as pruritus, erythema, and oedema (34). H2R activates the cyclic adenosine monophosphate (AMP)-dependent pathway and participates in cytokine production by Th1 lymphocytes. H3R and H4R have been involved in the activation of mitogenactivated protein (MAP) kinase. In addition, stimulation of H4R deploys $\mathrm{Ca}^{2+}$ ions stored inside the cells (35). In mice, deletion of $\mathrm{H} 1 \mathrm{R}$ causes dominant secretion of $\mathrm{Th} 2$ cytokines from $T$ cells upon activation, mainly interleukin (IL) 4 and IL-13, as well as suppression of interferon $\gamma($ IFN- $\gamma)(36)$. Recently conducted studies have shown that intradermal injection of IL-4 and IL-13 increase scratching behaviour in mice (37). In contrast, the allergen-challenged H1R-knockout mice were found to have reduced lung Th2 cytokines and thus lowered airway inflammation and hyper-responsiveness (38). Histamine promotes T-cell chemotaxis, impairment of which may be responsible for reducing lung inflammation.

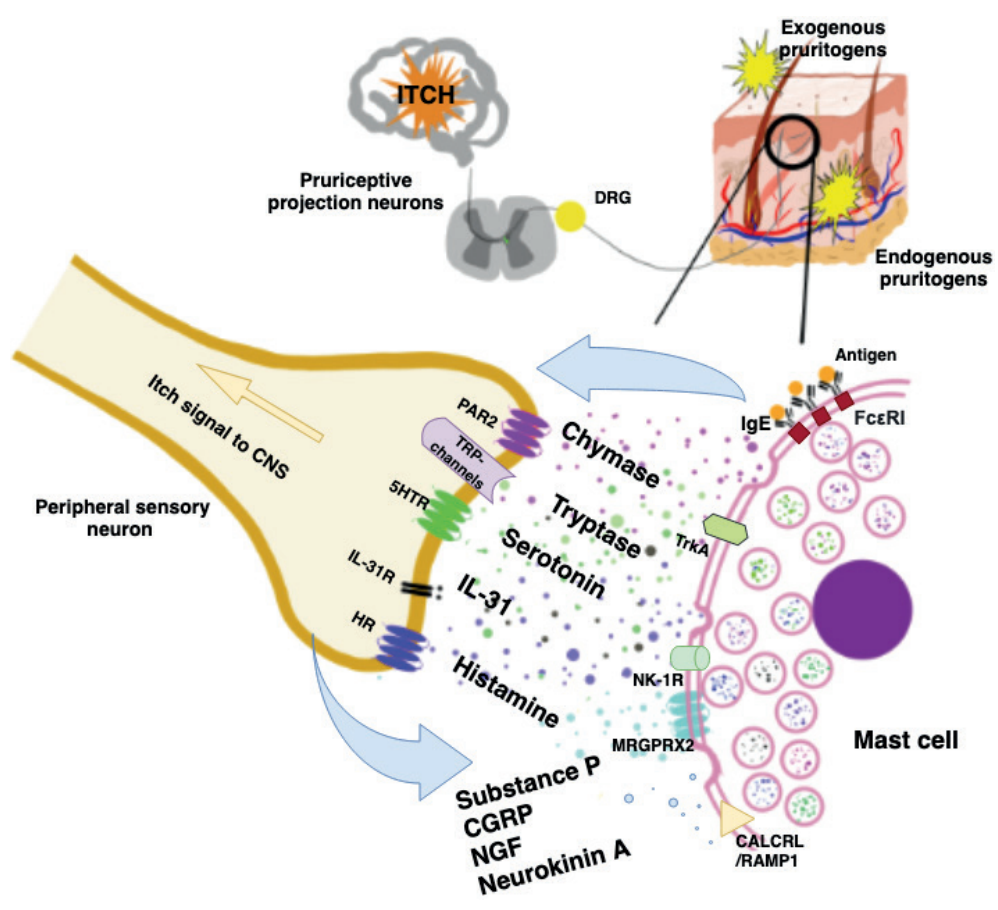

Fig. 2. Proposed model of the functional interaction between mast cells and the synapse of the sensory nerve in the skin. Immunoglobulin E (IgE) bounds antigens (different allergens) and triggers the IgE receptor FcERI signalling pathway, which results in mast cell degranulation. Mast cells release various mediators, such as chymase, tryptase, serotonin, histamine, and interleukins (including interleukin (IL)-31). Transmitters released from mast cells interact with their specific receptors (protease-activated receptor (PAR-2), serotonin receptor 5HTR, histamine receptor (HR), interleukin 31 receptor (IL-31R)) on nerve terminals, which leads to direct activation of pruriceptors. Stimulation of PAR-2 receptors leads to coactivation of transient receptor potential channels (TRP channels). In turn, activated nerve fibres release several mediators, including neuropeptides, such as calcitonin gene-related peptide (CGRP), substance $P$, nerve growth factor (NGF) and neurokinin 1, which elicit feedback activation of the mast cell through respective receptors (Masrelated G protein-coupled receptor-X2 (MGPRX2), neurokinin 1 receptor (NK-1R), tropomyosin receptor kinase $A(\operatorname{TrkA})$ ). CALCRL/RAMP1: calcitonin receptor-like receptor/receptor activity-modifying protein 1; DRG: dorsal root ganglion. 
These findings account for important regulatory mechanisms. Furthermore, histamine increases nerve growth factor (NGF) production via H1Rinduced signalling cascade in human keratinocytes. NGF is a proinflammatory mediator associated with pain and itch, which elicits crucial effects on the development and functions of sensory nerves. Regarding neurogenic inflammation, histamine showed a bidirectional mechanism of action based on close functional relationship with the nervous system. Acting through several distinct GPCRs expressed on sensory cutaneous neurones, histamine stimulates the release of various neuropeptides, including NGF, substance $\mathrm{P}$, calcitonin gene-related peptide (CGRP), and endothelin 1 (ET-1), from nerve terminals into the microenvironment. On the other hand, NGF, substance $\mathrm{P}$, and CGRP retrogradely activate mast cells to secrete histamine $(39,40)$. The H4R is a recently described histamine receptor and is expressed on mast cells, NK cells, dendritic cells, eosinophils, basophils and human $\mathrm{CD}^{+} \mathrm{T}$ cells (41). This receptor has been associated with inflammation and pruritus in a murine Th-2 dependent skin inflammation model (42). Interestingly, H4R stimulation leads to upregulation of IL-31 (43). Increased levels of IL-31 were found in lesions of allergic contact dermatitis and atopic dermatitis. It is now thought that IL-31 is an important mediator in the pathogenesis of various subtypes of pruritus.

\section{Serotonin}

Despite the fact that serotonin is scarcely found in human mast cell granules, it seems to remain a relevant mediator in mastocytosis (44). In addition to mast cells, many other epidermal and dermal cells possess the ability to express and secrete serotonin. Serotonin receptors (5-HTR) and transporters have been detected in keratinocytes, melanocytes, dermal fibroblasts, and sensory nerve endings. The abundance of 5-HTRs complicates understanding of the exact mechanisms by which serotonin could cause pruritus. To evaluate the pruritogenic activity of serotonin, Yamaguchi et al. (45) investigated whether intradermal injection of serotonin would induce itch-associated behaviours in mice. Findings from this study suggested that pruritogenic response to serotonin may be at least partially mediated by cutaneous 5-HT2Rs (45). Another study conducted by Nojima et al. (46) confirmed that 5-HT2R is involved in robust scratching behaviour in rodents. However, this study also showed that different mechanisms of action are relevant in dinitrofluorobenzene-induced pruritus in rats, which indicates that serotonin acting through 5HT2R or 5-HT3R is not markedly involved in allergic pruritus (46). The mechanism through which serotonin induces itch seems to be associated with transient receptor potential cation channel subfamily V member 4 (TRPV-4) dependent pathway (47-49). Interestingly, other pruritogens, such as histamine, chloroquine, and the protease active receptor (PAR) 2/Mas-related G-protein coupled receptor member A3 (MrgprA3) agonist SLIGRL did not show mediation via TRPV4.

The importance of serotonin in itch in humans remains controversial, as human mast cells contain only minute amounts of serotonin. However, given that patients with mastocytosis may have abnormal levels of serotonin, TRPV4 antagonists might be a promising treatment option for chronic itch (50). Novel studies have shown that serotonin may also induce chronic and acute itch by direct activation of the 5-HT7 receptor, expressed in cutaneous primary afferent sensory neurones (51). Within this process, the cation channel transient receptor potential ankyrin 1 (TRPA1) seems to be critical for itch transmission. A mouse model of atopic dermatitis without HTR7 or TRPA1 showed a reduced tendency to scratch. Since serotonin can be released independently of histamine, antihistamines often did not reduce pruritus induced by serotonin. However, it seems that both 5-HT2 and 5-HT7 receptor antagonists might be considered as new antipruritic treatment options in the future.

\section{Proteases}

Secretory granules of dermal mast cells store several serine proteinases: chymase, tryptase, and cathepsin-G. Histamine-independent pruritogens can mediate itch through G-protein-coupled PARs. PARs are expressed by primary sensory neurones, keratinocytes and immune cells, and are activated by proteases, the increased levels of which contribute to inflammation and pruritus. The expression and function of PARs differ between tissues and neural cells. PAR-2 is often increased in pruritic dermatoses (52). In mice models, tryptase-evoked scratching behaviour was inhibited by genetic knockout of PAR-2 (53). Tryptase is a prevalent protein that is released upon activation of mast cells and interacts with a PAR-2 on $\mathrm{C}$-fibre endings $(54,55)$. Stimulation of PAR-2 leads to coactivation of TRPV 1 channels and release of neuropeptides, including substance P and CGRP $(52,56,57)$. In turn, this process enhances neurogenic inflammation and in consequence, increases pruritus. The serum tryptase level reflects the total burden of mast cells; thus, it was suggested as an important diagnostic marker for systemic mastocytosis (58).

\section{Neuropeptides}

Unmyelinated C-fibres and myelinated A-delta fibres have the ability not only to transmit nerve impulses to secondary neurones, but also to release secretory vesicles containing various neuropeptides (59). Neuropeptides represent a large class of important signalling molecules that participate in the communication between sensory neurones and effector cells. During neurogenic inflammation, various mediators secreted by mast cells can alter 
the function of the sensory nerves and increase the release of neuropeptides (60). Essential neuropeptides associated with neurogenic inflammation comprise substance P (SP), CGRP, ET-1, NGF and neurokinin A (NK-A).

Substance $P$. SP is a proinflammatory neuropeptide and endogenous pruritogen of afferent neurones in the peripheral and central nervous system. SP elicits pruritus indirectly by activation of neurokinin-1 receptor (NK-1R) or Mas-related G protein coupled receptor-X2 (MRGPRX2). These data suggest that the NK-1R antagonist, aprepitant, might be a potential therapeutic option for itch in mastocytosis; however, this requires further investigation (61). Sensitization of mast cells leads to increased production of tumour necrosis factor $\alpha$ (TNF- $\alpha$ ), which further induces sensory nerve endings to release SP and thus creates a cycle of reciprocal activation. SP can induce the release of histamine, presumably only at high concentrations, and this reaction coexists with the wheal and flare reaction typically observed after histamine injections (62). Moreover, SP-positive nerve fibres can activate other cells, such as keratinocytes, endothelial cells, and immune cells, to produce other pruritogenic substances.

Calcitonin-gene related peptide. The sensitized peripheral nerve endings, Langerhans cells, and keratinocytes have the ability to express CGRP, which is considered a potent vasodilator (63). Although its role in induction of pruritus remains controversial, CGRP can modulate itch sensation through the loop of neuro-immune activation. CGRP targets calcitonin receptor-like receptor/ receptor activity-modifying protein 1 (CALCRL/ RAMP1) expressed on mast cells, which stimulate them to degranulate histamine. On the other hand, the administration of histamine induces the release of CGRP into the cerebrospinal fluid and the trigeminal ganglion (64). Interestingly, intradermal injection of CGRP elicits flare reaction, but never wheals, as in the case of histamine, even if CGRP is administrated after histamine.

Endothelin-1. Another neuropeptide that evokes histamine-independent pruritus and was initially shown to have vasoactive and pro-inflammatory properties is ET-1 (65). This polypeptide has lots of regulatory functions and is involved in pathways of pain and inflammation (66). Upon stimulation, various cells can release ET-1, which elicits its biological effects via induction of 2 distinct receptors, endothelin A receptor (ETAR) present mainly on mast cells and sensory neurones, and endothelin B receptor (ETBR). Although ET-1 induces the release of mast cell mediators, itching after ET-1 administration is only partially mediated by histamine (67). Intradermal administration of ET-1 causes pruritus mediated through ETAR, as well as local erythema; however, without wheal, which is typical for histamine (68).

Nerve growth factor. NGF is the first discovered and well-characterized member of the neurotrophin family that accomplishes many regulatory functions. NGF has essential effects on the development and neurobiology of sensory nerves. Intradermal administration of NGF induces sensitization of nociceptors. Increased serum level of NGF was observed in patients with mastocytosis (69). In addition, in patients with atopic dermatitis, chronic pruritus has been linked to increased levels of NGF (70). NGF lowers itch tolerance by neuronal elongation and indirectly aggravates pruritus. Increased levels of NGF along with a higher density of nerve fibres have also been shown in patients with contact dermatitis, suggesting a functional role in cutaneous inflammation (71). Moreover, activation of the NGF receptor tyrosine kinase TrkA on nociceptive neurones has been found in mice models as a trigger for systemic mastocytosis and potential player in the development of resistance to KIT-targeted therapy (72).

Neurokinin A. NK-A belongs to the family of tachykinins that selectively binds to and activates GPCRs, including the NK1R. The NK1R is expressed on various cells, including mast cells, keratinocytes, fibroblasts, as well as in the superficial lamina I dorsal horn neurones of the spinal cord. Increased NK-1R expression was observed in patients with prurigo nodularis and chronic pruritus (73). Moreover, ablation of NK-1-expressing spinal neurones in rats inhibited acute and chronic itch (74). Whether NK-A plays a significant role in pruritus related to mastocytosis, has yet to be elucidated.

\section{Interleukin-31}

Numerous studies have been carried out on the effects of different cytokines in the pathogenesis of pruritus (75). Research conducted by Hartmann et al. for the first time showed elevated levels of interleukin (IL)-31 in the serum of patients with mastocytosis (76). Moreover, it was noted that IL-31 level in serum is juxtaposed with disease severity, tryptase levels, and percentages of bone marrow infiltration in adult patients. Manifold data indicate that IL-31 may also be the major trigger of pruritus in mastocytosis (77). Several cell types possessing the capacity of producing IL-31 have been described so far, including Th2 cells, mast cells, macrophages, and dendritic cells (78). Receptors for IL-31 reside on neurones of human dorsal root ganglions (79). Binding of IL-31 to its receptor activates JAK/STAT, PI3K/AKT and MAPK signalling cascades. Presently, the JAK2-STAT5 pathway is considered as the most valid for growth and survival of mast cells. It was hypothesized, that interference with the JAK2-STAT5 pathway may inhibit the degranulation of mast cells. Recent studies have shown that ruxolitinib, a novel JAK $1 / 2$ inhibitor, is effective in reducing cytokine production and thus represents an interesting new treatment option that can potentially alleviate pruritus in mastocytosis (80). 


\section{Mas-related $G$ protein-coupled receptors}

Members of the Mas-related G protein-coupled receptor (Mrgpr) family have been identified as mast cell receptors fulfilling an integral role in mast cell degranulation, sensory neurone activation, and non-histaminergic pruritus (81). However, many aspects of Mrgpr's action in mediating an itch sensation remain unclear. The important role of a human G-protein coupled receptor, MRGPRX2, in the activation of mast cells through a nonIgE mechanism is currently emphasized. MRGPRX2 has been shown to be activated by basic secretagogues, that promote degranulation independently from FceRI. Meixiong et al. compared activation of mast cells via Mrgprb2 and IgE-FceRI, demonstrating the subsequent activation of different sets of itch sensory neurones (82). The above results explain why blocking the histamine $\mathrm{H} 1 \mathrm{R}$ is not always effective in treating pruritus in mastocytosis, as alternate pathways may also play a significant role.

\section{PRURITUS FROM A CLINICAL POINT OF VIEW}

In clinical practice, pruritus is a common symptom in patients with mastocytosis. The exact prevalence of pruritus in this disease has not been fully elucidated. However, in studies by Lange et al. pruritus was present in 65 of 78 adult patients and in 68 of 100 paediatric patients with mastocytosis $(77,83)$. In another study, urticaria pigmentosa was found to be associated with generalized pruritus in 10 out of 30 patients (84). In addition, itch was described as a primary symptom in 42 of 67 paediatric patients with urticaria pigmentosa $(85)$.

A key aspect of management of cutaneous mastocytosis is the alleviation of mast cell-associated symptoms, including pruritus (86). The diversity of mediators makes the effective therapy of pruritus challenging (87). Patients should be instructed about potential mast cell degranulating triggers, which can exacerbate the symptoms of mastocytosis, such as venoms, solar radiation, various food allergens, spicy spices, alcohol, selected drugs, infections, and emotional stress (88). Although antihistamines are not always effective, this group of medications remains an important first-line treatment strategy (89). The second-generation, non-sedating $\mathrm{H} 1$ antihistamines may be tried first to mitigate itch (86). To date, the effectiveness of rupatadine in ameliorating mediator-related symptoms of mastocytosis has been documented in one randomized, double-blind and placebo-controlled, cross-over clinical trial, showing better control of mast cell mediator-related symptoms and improved patients' quality of life in actively treated subjects (90). The dose of antihistamines can be increased four-fold, as in patients with urticaria, albeit the efficacy of such strategy was not verified in mastocytosis (91). In addition, several studies have shown that concomitant treatment with $\mathrm{H} 1$ and $\mathrm{H} 2$ antihistamines can also be helpful in controlling intense pruritus (92). There is increasing evidence that suggests that selective H4 antihistamines may also have a therapeutic utility in patients with chronic pruritus, although further data are still required $(35,93)$.

In cases of persistence pruritus, narrow-band ultraviolet B (NB-UVB) and UVA therapy, either alone or combined with oral psoralen, may be considered (94-96). In a study by Gobello et al., UVA1 phototherapy has been found to alleviate pruritus and induce long-term remission in most cases of adult patients with urticaria pigmentosa (97). Moreover, UVB may play an important role in the induction of mast cell apoptosis. Based on research by Szepietowski et al. (98), it can be hypothesized that NB-UVB phototherapy could be effective for several diseases dependent on the increased number of cutaneous mast cells. It is worth noting that uraemic pruritus, which is also associated with excessive proliferation of mast cells in the skin, can be effectively controlled with NB-UVB (99-101). There is emerging evidence that IL-31 plays a role in pruritus in patients with mastocytosis, suggesting that nemolizumab, a potent anti-IL-31 monoclonal antibody, has the potential to be effective in this group of patients, albeit this suggestion needs to be confirmed in clinical settings (102). Another treatment option for pruritus unresponsive to traditional therapies with antihistamines could be omalizumab, the anti-IgE monoclonal antibody, which might block mast cell activity (103). Interestingly, the NK-1 inhibitor, aprepitant, developed for the prevention of chemotherapy-induced nausea and vomiting, seemed to possess some antipruritic properties, as well as some other NK-1 inhibitors (serlopitant and tradipitant) might also provide some benefit in the treatment of pruritus (104-106). Nevertheless, in a multicentre, randomized, phase III trial, aprepitant did not show significant benefit over placebo in patients with chronic prurigo (107). In contrast, serlopitant was shown to significantly reduce pruritus in phase II trial in psoriasis (108). However, studies on serlopitant in prurigo nodularis have been stopped prematurely due to lack of statistically significant improvement in itch severity, despite the data showed a numerical advantage for serlopitant compared with placebo on the primary endpoint.

There are currently several other promising compounds that have the potential to become potent antipruritic treatments. Findings from a randomized, placebo-controlled, phase 3 study indicate that masitinib, an orally administered tyrosine kinase inhibitor, could be an effective and well-tolerated agent (109). Lately, JAK inhibitors are being investigated for use in chronic itch. In 2 randomized, phase III clinical trials, tofacitinib significantly improved itching in patients with psoriasis $(110,111)$, whereas in a study on 5 patients with refractory, chronic, and idiopathic pruritus, treatment with oral tofacitinib markedly improved pruritus after only 1 month of treatment (112). Furthermore, topical tofacitinib was found to be effective 
for treating pruritus in patients with atopic dermatitis (113). In addition, topical administration of tofacitinib and oclacitinib resulted in reduction of pruritus and inflammatory response in mouse models (114). Finally, ruxolitinib, another selective JAK inhibitor, which has been shown to inhibit mast cell degranulation, is also an interesting therapy option to alleviate pruritus (83).

In conclusion, the role of mast cells in the pathogenesis of pruritus in mastocytosis is complex. Proper management of this disorder requires a deep comprehension of its molecular pathogenesis. A better understanding of the reciprocal crosstalk between mast cells, peripheral sensory nerves, and the exact role of different mediators in the pathogenesis of pruritus could bring new and more effective therapeutic strategies for this group of patients in the near future.

\section{ACKNOWLEDGEMENTS}

Conflicts of interest. DK has no conflicts of interest to declare. AR has worked as a consultant or speaker for AbbVie, Bioderma, Celgene, Chema Elektromet, Eli Lilly, Galderma, Janssen, Leo Pharma, Medac, Menlo Therapeutics, Novartis, Pierre-Fabre, Sandoz, and Trevi, and participated as principal investigator or subinvestigator in clinical trials sponsored by AbbVie, Drug Delivery Solutions Ltd, Galderma, Genentech, Janssen, Kymab Limited, Leo Pharma, Menlo Therapeutics, MetrioPharm, MSD, Novartis, Pfizer, and Trevi.

\section{REFERENCES}

1. Reich A, Szepietowski JC. Diagnostic procedures of itch. Curr Probl Dermatol 2016; 50: 24-28.

2. Carter MC, Metcalfe DD, Komarow HD. Mastocytosis. Immunol Allergy Clin North Am 2014; 34: 181-196.

3. Le M, Miedzybrodzki B, Olynych T, Chapdelaine H, BenShoshan M. Natural history and treatment of cutaneous and systemic mastocytosis. Postgrad Med 2017; 129: 896-901.

4. Valent $P$, Akin C, Metcalfe DD. Mastocytosis: 2016 updated WHO classification and novel emerging treatment concepts. Blood 2017; 129: 1420-1427.

5. Bulat V, Mihić LL, Šitum M, Buljan M, Blajić I, Pušić J. Most common clinical presentations of cutaneous mastocytosis. Acta Clin Croat Suppl 2009; 48: 59-64.

6. Shomali W, Gotlib J. The new tool "kIT" in advanced systemic mastocytosis. Hematol (United States) 2018; 2018: 127-136.

7. Moon TC, St Laurent CD, Morris KE, Marcet C, Yoshimura T, Sekar $Y$, et al. Advances in mast cell biology: new understanding of heterogeneity and function. Mucosal Immunol 2010; 3: 111-128.

8. Galli SJ, Grimbaldeston M, Tsai M. Immunomodulatory mast cells: negative, as well as positive, regulators of immunity. Nat Rev Immunol 2008; 8: 478-486.

9. Lubbers R, van Essen MF, van Kooten C, Trouw LA. Production of complement components by cells of the immune system. Clin Exp Immunol 2017; 188: 183-194.

10. Dong $H$, Zhang $X$, Qian $Y$. Mast cells and neuroinflammation. Med Sci Monit Basic Res 2014; 20: 200-206.

11. Skaper SD, Facci L, Giusti P. Mast cells, glia and neuroinflammation: partners in crime? Immunology 2014; 141: 314-327.

12. Dahlin JS, Malinovschi A, Öhrvik $H$, Sandelin $M$, Janson C, Alving K, et al. Lin- CD34hi CD117Int/hi FcERI+ cells in human blood constitute a rare population of mast cell progenitors. Blood 2016; 127: 383-391.
13. Schmetzer $O$, Valentin $P$, Church MK, Maurer M, Siebenhaar F. Murine and human mast cell progenitors. Eur J Pharmacol 2016; 778: 2-10.

14. Walczak-Drzewiecka A, Salkowska A, Ratajewski M, Dastych J. Epigenetic regulation of CD34 and HIF1A expression during the differentiation of human mast cells. Immunogenetics 2013; 65: 429-348.

15. Silverman AJ, Sutherland AK, Wilhelm M, Silver R. Mast cells migrate from blood to brain. J Neurosci 2000; 20: 401-408.

16. Skaper SD, Giusti P, Facci L. Microglia and mast cells: two tracks on the road to neuroinflammation. FASEB J 2012; 26: 3103-3117.

17. Matsson L. Mast cell heterogeneity in various oral mucosal sites in the rat. Arch Oral Biol 1992; 37: 445-450.

18. Castells M, Butterfield J. Mast cell activation syndrome and mastocytosis: initial treatment options and long-term management. J Allergy Clin Immunol Pract 2019; 7: 1097-1106.

19. Finn DF, Walsh JJ. Twenty-first century mast cell stabilizers. Br J Pharmacol 2013; 170: 23.

20. Oka T, Kalesnikoff J, Starkl P, Tsai M, Galli SJ. Evidence questioning cromolyn's effectiveness and selectivity as a "mast cell stabilizer" in mice. Lab Invest 2012; 92: 1472.

21. Song J, Xian D, Yang L, Xiong X, Lai R, Zhong J. Pruritus: progress toward pathogenesis and treatment. Biomed Res Int 2018; 2018: 9625936.

22. Azimi E, Xia J, Lerner EA. Peripheral mechanisms of itch. Curr Probl Dermatol 2016; 50: 18.

23. Weber A, Knop J, Maurer M. Pattern analysis of human cutaneous mast cell populations by total body surface mapping. Br J Dermatol 2003; 148: 224-228.

24. Tikoo S, Barki N, Jain R, Zulkhernain NS, Buhner S, Schemann $M$, et al. Imaging of mast cells. Immunol Rev 2018; 282: $58-72$.

25. Frossi B, Mion F, Sibilano R, Danelli L, Pucillo CEM. Is it time for a new classification of mast cells? What do we know about mast cell heterogeneity? Immunol Rev 2018; 282: 35-46.

26. Hendriksen E, van Bergeijk D, Oosting RS, Redegeld FA. Mast cells in neuroinflammation and brain disorders. Neurosci Biobehav Rev 2017; 79: 119-133.

27. Janssens AS, Heide R, Den Hollander JC, Mulder PGM, Tank B, Oranje AP. Mast cell distribution in normal adult skin. J Clin Pathol 2005; 58: 285-289.

28. Siiskonen H, Harvima I. Mast cells and sensory nerves contribute to neurogenic inflammation and pruritus in chronic skin inflammation. Front Cell Neurosci 2019; 18; 13.

29. Chang SE, Han SS, Jung HJ, Choi JH. Neuropeptides and their receptors in psoriatic skin in relation to pruritus. $\mathrm{Br}$ J Dermatol 2007; 156: 1272-1277.

30. Shim WS, Oh U. Histamine-induced itch and its relationship with pain. Mol Pain 2008; 4: 29.

31. Pentland AP, Mahoney M, Jacobs SC, Holtzman MJ. Enhanced prostaglandin synthesis after ultraviolet injury is mediated by endogenous histamine stimulation. A mechanism for irradiation erythema. J Clin Invest 1990; 86: 566-574.

32. Esbenshade TA, Fox GB, Cowart MD. Histamine $\mathrm{H} 3$ receptor antagonists: preclinical promise for treating obesity and cognitive disorders. Mol Interv 2006; 6: 77-88.

33. Thurmond RL. The histamine $\mathrm{H} 4$ receptor: from orphan to the clinic. Front Pharmacol 2015; 6: 65.

34. Ohtsu $H$, Seike M. Histamine and histamine receptors in allergic dermatitis. Handb Exp Pharmacol 2017; 241: 333-345.

35. Dunford PJ, Williams KN, Desai PJ, Karlsson L, McQueen $\mathrm{D}$, Thurmond RL. Histamine $\mathrm{H} 4$ receptor antagonists are superior to traditional antihistamines in the attenuation of experimental pruritus. J Allergy Clin Immunol 2007; 119: 176-183.

36. Jutel M, Watanabe T, Klunker S, Akdis M, Thomet OAR, Malolepszy J, et al. Histamine regulates T-cell and antibody responses by differential expression of $\mathrm{H} 1$ and $\mathrm{H} 2$ receptors. Nature 2001; 413: 420-425.

37. Campion M, Smith L, Gatault S, Métais C, Buddenkotte J, Steinhoff M. Interleukin-4 and interleukin-13 evoke scratching behaviour in mice. Exp Dermatol 2019; 28: 
$1501-1504$.

38. Bryce PJ, Mathias CB, Harrison KL, Watanabe T, Geha RS, Oettgen $\mathrm{HC}$. The $\mathrm{H} 1$ histamine receptor regulates allergic lung responses. J Clin Invest 2006; 116: 1624-1632.

39. Gaudenzio N, Sibilano R, Marichal T, Starkl P, Reber LL, Cenac N, et al. Different activation signals induce distinct mast cell degranulation strategies. J Clin Invest $2016 ; 126$ : 3981-3998.

40. Guhl S, Lee HH, Babina M, Henz BM, Zuberbier T. Evidence for a restricted rather than generalized stimulatory response of skin-derived human mast cells to substance P. J Neuroimmunol 2005; 163: 92-101.

41. Oda T, Morikawa N, Saito Y, Masuho Y, Matsumoto SI. Molecular cloning and characterization of a novel type of histamine receptor preferentially expressed in leukocytes. J Biol Chem 2000; 275: 36781-36786.

42. Cowden JM, Zhang M, Dunford PJ, Thurmond RL. The histamine $\mathrm{H} 4$ receptor mediates inflammation and pruritus in Th2-dependent dermal inflammation. J Invest Dermatol 2010; 130: 1023-1033.

43. Gutzmer R, Mommert S, Gschwandtner M, Zwingmann K, Stark $\mathrm{H}$, Werfel $\mathrm{T}$. The histamine $\mathrm{H} 4$ receptor is functionally expressed on TH2 cells. J Allergy Clin Immunol 2009; 123 : 619-625.

44. Kritas SK, Saggini A, Cerulli G, Caraffa A, Antinolfi P, Pantalone $A$, et al. Relationship between serotonin and mast cells: inhibitory effect of anti-serotonin. J Biol Regul Homeost Agents 2014; 28: 377-380.

45. Yamaguchi T, Nagasawa T, Satoh M, Kuraishi Y. Itch-associated response induced by intradermal serotonin through 5-HT2 receptors in mice. Neurosci Res 1999; 35: 77-83.

46. Nojima H, Carstens E. 5-Hydroxytryptamine (5-HT)2 receptor involvement in acute 5-HT-evoked scratching but not in allergic pruritus induced by dinitrofluorobenzene in rats. J Pharmacol Exp Ther 2003; 306: 245-252.

47. Luo J, Feng J, Yu G, Yang P, Mack MR, Du J, et al. Transient receptor potential vanilloid 4-expressing macrophages and keratinocytes contribute differentially to allergic and nonallergic chronic itch. J Allergy Clin Immunol 2018; 141: 608-619.

48. Akiyama T, Ivanov M, Nagamine M, Davoodi A, Carstens MI, Ikoma $A$, et al. Involvement of TRPV4 in serotonin-evoked scratching. J Invest Dermatol 2016; 136: 154-160.

49. Snyder LM, Kuzirian MS, Ross SE. An unexpected role for TRPV4 in serotonin-mediated itch. J Invest Dermatol 2016; 136: 7-9.

50. Kushnir-Sukhov NM, Brittain E, Scott L, Metcalfe DD. Clinical correlates of blood serotonin levels in patients with mastocytosis. Eur J Clin Invest 2008; 38: 953-958.

51. Morita T, McClain SP, Batia LM, Pellegrino M, Wilson SR, Kienzler MA, et al. HTR7 mediates serotonergic acute and chronic itch. Neuron 2015; 87: 124-138.

52. Steinhoff M, Neisius U, Ikoma A, Fartasch M, Heyer G, Skov PS, et al. Proteinase-activated receptor-2 mediates itch: a novel pathway for pruritus in human skin. J Neurosci 2003; 16 ; 23: 6176-6180.

53. Ui H, Andoh T, Lee JB, Nojima H, Kuraishi Y. Potent pruritogenic action of tryptase mediated by PAR-2 receptor and its involvement in anti-pruritic effect of nafamostat mesilate in mice. Eur J Pharmacol 2006; 530: 172-178.

54. Kempkes C, Buddenkotte J, Cevikbas F, Buhl T, Steinhoff M. Role of PAR-2 in neuroimmune communication and itch. In: Carstens E, Akiyama T, editors. Itch: mechanisms and treatment. Boca Raton (FL): CRC Press/Taylor \& Francis, 2014: p. 193-212.

55. Vitte J. Human mast cell tryptase in biology and medicine. Mol Immunol 2015; 63: 18-24.

56. Steinhoff M, Vergnolle N, Young SH, Tognetto M, Amadesi S, Ennes HS, et al. Agonists of proteinase-activated receptor 2 induce inflammation by a neurogenic mechanism. Nat Med 2000; 6: 151-158.

57. Dai Y, Moriyama T, Higashi T, Togashi K, Kobayashi K, Yamanaka $\mathrm{H}$, et al. Proteinase-activated receptor 2-mediated potentiation of transient receptor potential vanilloid subfa- mily 1 activity reveals a mechanism for proteinase-induced inflammatory pain. J Neurosci 2004; 24: 4293-4299.

58. Sperr WR, Jordan JH, Fiegl M, Escribano L, Bellas C, Dirnhofer $S$, et al. Serum tryptase levels in patients with mastocytosis: Correlation with mast cell burden and implication for defining the category of disease. Int Arch Allergy Immunol 2002; 128: 136-141.

59. Pierau F-K, Sann H, Müller S. Regulation of efferent functions of C-fiber nociceptors. In: Thermotherapy for neoplasia, inflammation, and pain. Tokyo: Springer, 2001: p. 514-522.

60. Chiu IM, Hehn CA von, Woolf CJ. Neurogenic inflammation - the peripheral nervous system's role in host defense and immunopathology. Nat Neurosci 2012; 15: 1063.

61. Pojawa-Gołąb M, Jaworecka K, Reich A. NK-1 receptor antagonists and pruritus: review of current literature. Dermatol Ther (Heidelb) 2019; 9: 391-405.

62. Hägermark Ö, Hökfelt T, Pernow B. Flare and itch induced by substance $P$ in human skin. J Invest Dermatol 1978; 71: 233-235.

63. Hou Q, Barr T, Gee L, Vickers J, Wymer J, Borsani E, et al. Keratinocyte expression of calcitonin gene-related peptide $\beta$ : Implications for neuropathic and inflammatory pain mechanisms. Pain 2011; 152: 2036-2051.

64. Eftekhari S, Warfvinge K, Blixt FW, Edvinsson L. Differentiation of nerve fibers storing CGRP and CGRP receptors in the peripheral trigeminovascular system. J Pain 2013; 14: 1289-1303.

65. Trentin PG, Fernandes MB, D'Orléans-Juste P, Rae GA. Endothelin-1 causes pruritus in mice. Exp Biol Med 2006; 231: 1146-1151.

66. Hans G, Deseure K, Adriaensen H. Endothelin-1-induced pain and hyperalgesia: a review of pathophysiology, clinical manifestations and future therapeutic options. Neuropeptides 2008; 42: 119-132.

67. Kremer AE, Feramisco J, Reeh PW, Beuers U, Oude Elferink RPJ. Receptors, cells and circuits involved in pruritus of systemic disorders. Biochim Biophys Acta - Mol Basis Dis 2014; 1842: 869-892.

68. Kido-Nakahara M, Buddenkotte J, Kempkes C, Ikoma A, Cevikbas F, Akiyama T, et al. Neural peptidase endothelinconverting enzyme 1 regulates endothelin 1 -induced pruritus. J Clin Invest 2014; 124: 2683-2695.

69. Peng WM, Maintz L, Allam JP, Raap U, Gutgemann I, Kirfel $\mathrm{J}$, et al. Increased circulating levels of neurotrophins and elevated expression of their high-affinity receptors on skin and gut mast cells in mastocytosis. Blood 2013; 122: 1779-1788.

70. Yamaguchi J, Aihara M, Kobayashi Y, Kambara T, Ikezawa Z. Quantitative analysis of nerve growth factor (NGF) in the atopic dermatitis and psoriasis horny layer and effect of treatment on NGF in atopic dermatitis. J Dermatol Sci 2009; 53: 48-54.

71. Kinkelin I, Mötzing S, Koltzenburg M, Bröcker EB. Increase in NGF content and nerve fiber sprouting in human allergic contact eczema. Cell Tissue Res 2000; 302: 31-37.

72. Yang $M$, Pan Z, Huang $K$, Büsche G, Feuerhake $F$, Chaturvedi $A$, et al. Activation of TRKA receptor elicits mastocytosis in mice and is involved in the development of resistance to KIT-targeted therapy. Oncotarget 2017; 8: 73871-73883.

73. Zeidler C, Ständer S. The pathogenesis of prurigo nodularis - "Super-Itch" in exploration. Eur J Pain (UK) 2016; 20: $37-40$.

74. Akiyama T, Nguyen T, Curtis E, Nishida K, Devireddy J, Delahanty J, et al. A central role for spinal dorsal horn neurons that express neurokinin-1 receptors in chronic itch. Pain 2015; 156: 1240-1246.

75. Takamori A, Nambu A, Sato K, Yamaguchi S, Matsuda K, Numata T, et al. IL-31 is crucial for induction of pruritus, but not inflammation, in contact hypersensitivity. Sci Rep 2018; 8: 1-11.

76. Rava M, Taresa L, Lavi I, Barreiro E, Zock JP, Ferrer A, et al. Serum levels of Clara cell secretory protein, asthma, and lung function in the adult general population. J Allergy Clin 
Immunol 2013; 132: 230-232.

77. Lange M, Gleń J, Zabłotna M, Nedoszytko B, SokołowskaWojdyło M, Rębała $K$, et al. Interleukin-31 polymorphisms and serum IL-31 level in patients with mastocytosis: Correlation with clinical presentation and pruritus. Acta Derm Venereol 2017; 97: 47-53.

78. Gibbs BF, Patsinakidis N, Raap U. Role of the pruritic cytokine IL-31 in autoimmune skin diseases. Front Immunol 2019; 10: 1383.

79. Zhang Q, Putheti $P$, Zhou Q, Liu Q, Gao W. Structures and biological functions of IL-31 and IL-31 receptors. Cytokine Growth Factor Rev 2008; 19: 347-356.

80. Hermans MAW, Schrijver B, van Holten-Neelen CCPA, Gerth van Wijk R, van Hagen PM, van Daele PLA, et al. The JAK1/JAK2- inhibitor ruxolitinib inhibits mast cell degranulation and cytokine release. Clin Exp Allergy 2018; 48: $1412-1420$

81. Meixiong J, Dong X. Mas-related G protein-coupled receptors and the biology of itch sensation. Annu Rev Genet 2017; 51: 103-121.

82. Meixiong J, Anderson M, Limjunyawong N, Sabbagh MF, $\mathrm{Hu}$ $E$, Mack MR, et al. Activation of mast-cell-expressed Mas-related G-protein-coupled receptors drives non-histaminergic itch. Immunity 2019; 50: 1163-1171.

83. Lange M, Niedoszytko M, Renke J, Gleń J, Nedoszytko B. Clinical aspects of paediatric mastocytosis: a review of 101 cases. J Eur Acad Dermatology Venereol 2013; 27: 97-102.

84. Topar G, Staudacher C, Geisen F, Gabl C, Fend F, Herold M, et al. Urticaria pigmentosa: a clinical, hematopathologic, and serologic study of 30 adults. Am J Clin Pathol 1998; 109: 279-285.

85. Azaña JM, Torrelo A, Mediero IG, Zambrano A. Urticaria pigmentosa: a review of 67 pediatric cases. Pediatr Dermatol 1994; 11: 102-106.

86. Czarny J, Lange M, Ługowska-Umer H, Nowicki RJ. Cutaneous mastocytosis treatment: strategies, limitations and perspectives. Adv Dermatol Allergol 2018; 35: 541-545.

87. Siebenhaar F, Akin C, Bindslev-Jensen C, Maurer M, Broesby-Olsen $\mathrm{S}$. Treatment strategies in mastocytosis. Immunol Allergy Clin North Am 2014; 34: 433-447.

88. Lange M, Flisiak I, Kapinska-Mrowiecka ML, Kaszuba A, Maj J, Rudnicka L, et al. Mastocytosis. Diagnostic and therapeutic recommendations of the Polish Dermatological Society. Dermatol Rev 2018; 105: 358-383.

89. Arock M, Akin C, Hermine O, Valent P. Current treatment options in patients with mastocytosis: Status in 2015 and future perspectives. Eur J Haematol 2015; 94: 474-490.

90. Siebenhaar F, Förtsch A, Krause K, Weller K, Metz M, Magerl $M$, et al. Rupatadine improves quality of life in mastocytosis: a randomized, double-blind, placebo-controlled trial. Allergy Eur J Allergy Clin Immunol 2013; 68: 949-952.

91. Zuberbier T, Aberer W, Asero R, Bindslev-Jensen C, Brzoza $\mathrm{Z}$, Canonica GW, et al. Methods report on the development of the 2013 revision and update of the EAACI/GA2LEN/EDF/ WAO guideline for the definition, classification, diagnosis, and management of urticaria. Allergy Eur J Allergy Clin Immunol 2014; 69: e1-29.

92. Gasior-Chrzan B, Falk ES. Systemic mastocytosis treated with histamine $\mathrm{H} 1$ and $\mathrm{H} 2$ receptor antagonists. Dermatology 1992; 184: 149-152.

93. Thangam EB, Jemima EA, Singh H, Baig MS, Khan M, Mathias $C B$, et al. The role of histamine and histamine receptors in mast cell-mediated allergy and inflammation: The hunt for new therapeutic targets. Front Immunol 2018; 9: 1873.

94. Brazzelli V, Grassi S, Merante S, Grasso V, Ciccocioppo R, Bossi G, et al. Narrow-band UVB phototherapy and psoralen-ultraviolet $A$ photochemotherapy in the treatment of cutaneous mastocytosis: a study in 20 patients. Photodermatol Photoimmunol Photomed 2016; 32: 238-246.

95. Godt O, Proksch E, Streit V, Christophers E. Short- and long-term effectiveness of oral and bath puva therapy in urticaria pigmentosa and systemic mastocytosis. Dermatology 1997; 195: 35-39.
96. Seckin D, Demircay Z, Akin O. Generalized pruritus treated with narrowband UVB. Int J Dermatol 2007; 46: 367-370.

97. Gobello T, Mazzanti C, Sordi D, Annessi G, Abeni D, Chinni LM, et al. Medium- versus high-dose ultraviolet A1 therapy for urticaria pigmentosa: a pilot study. J Am Acad Dermatol 2003; 49: 679-684.

98. Szepietowski JC, Morita A, Tsuji T. Ultraviolet B induces mast cell apoptosis: a hypothetical mechanism of ultraviolet $B$ treatment for uraemic pruritus. Med Hypothes 2002; 58: 167-170.

99. Szepietowski J, Thepen T, van Vloten WA, Szepietowski T, Bihari IC. Pruritus and mast cell proliferation in the skin of haemodialysis patients. Inflamm Res 1995; 44: 84-85.

100. Matsumoto M, Ichimaru K, Horie A. Pruritus and mast cell proliferation of the skin in end stage renal failure. Clin Nephrol 1985; 23: 285-288.

101. Dimković N, Djukanović L, Radmilović A, Bojić $P$, Juloski T. Uremic pruritus and skin mast cells. Nephron 1992; 61: 5-9.

102. Bağci IS, Ruzicka T. IL-31: a new key player in dermatology and beyond. J Allergy Clin Immunol 2018; 141: 858-866.

103. Hinojosa T, Lewis DJ, Vangipuram R, Safeer L, Mui UN, Haley $C$, et al. The efficacy of omalizumab in Cutaneous Mastocytosis: a case series. Dermatol Ther 2019; 32: e12848.

104. Yosipovitch G, Ständer S, Kerby MB, Larrick JW, Perlman AJ, Schnipper EF, et al. Serlopitant for the treatment of chronic pruritus: results of a randomized, multicenter, placebocontrolled phase 2 clinical trial. J Am Acad Dermatol 2018; 78: 882-891.

105. Ständer S, Kwon P, Hirman J, Perlman AJ, Weisshaar E, Metz $M$, et al. Serlopitant reduced pruritus in patients with prurigo nodularis in a phase 2 , randomized, placebo-controlled trial. J Am Acad Dermatol 2019; 80: 1395-1402.

106. Heitman A, Xiao C, Cho Y, Polymeropoulos C, Birznieks G, Polymeropoulos M. Tradipitant improves worst itch and disease severity in patients with chronic pruritus related to atopic dermatitis. J Am Acad Dermatol 2018; 79: AB300.

107. Tsianakas A, Zeidler C, Riepe C, Borowski M, Forner C, Gerss $\mathrm{J}$, et al. Aprepitant in anti-histamine-refractory chronic nodular prurigo: a multicentre, randomized, double-blind, placebo-controlled, cross-over, phase-II trial (APREPRU). Acta Derm Venereol 2019; 99: 379-385.

108. Pariser DM, Bagel J, Lebwohl M, Yosipovitch G, Chien E, Spellman MC. Serlopitant for psoriatic pruritus: a phase 2 randomized, double-blind, placebo-controlled clinical trial. J Am Acad Dermatol 2020; 82: 1314-1320.

109. Lortholary O, Chandesris MO, Livideanu CB, Paul C, Guillet $G$, Jassem $E$, et al. Masitinib for treatment of severely symptomatic indolent systemic mastocytosis: a randomised, placebo-controlled, phase 3 study. Lancet 2017; 389: 612-620.

110. Feldman SR, Thaçi D, Gooderham M, Augustin M, de la Cruz C, Mallbris L, et al. Tofacitinib improves pruritus and health-related quality of life up to 52 weeks: results from 2 randomized phase III trials in patients with moderate to severe plaque psoriasis. J Am Acad Dermatol 2016; 75: 1162-1170.

111. Ständer S, Luger TA, Cappelleri JC, Bushmakin AG, Mamolo C, Zielinski MA, et al. Validation of the itch severity item as a measurement tool for pruritus in patients with psoriasis: results from a phase 3 tofacitinib program. Acta Derm Venereol 2018; 98: 340-345.

112. Oetjen LK, Mack MR, Feng J, Whelan TM, Niu H, Guo CJ, et al. Sensory neurons co-opt classical immune signaling pathways to mediate chronic itch. Cell 2017; 171: 217-228.

113. Bissonnette R, Papp KA, Poulin Y, Gooderham M, Raman $M$, Mallbris $L$, et al. Topical tofacitinib for atopic dermatitis: a phase IIa randomized trial. $\mathrm{Br}$ J Dermatol 2016; 175: 902-911.

114. Fukuyama T, Ehling S, Cook E, Bäumer W. Topically administered janus-kinase inhibitors tofacitinib and oclacitinib display impressive antipruritic and anti-inflammatory responses in a model of allergic dermatitis. J Pharmacol Exp Ther 2015; 354: 394-405. 